\section{Mental handicap resettlement readmissions}

Sir: Between 1982 and 1994, 220 mentally handicapped in-patients (111 men, 109 women) were resettled from Meanwood Park Hospital, Leeds. Twenty-three stayed under the care of the NHS in community houses and bungalows. The others were discharged to live mainly in group homes for 4 or 5 residents run by various caring agencies.

Twenty-two of the patients (11 men, 11 women), have returned to hospital since April 1985. Three have been readmitted twice. Twelve patients (10 men, 2 women) are still in hospital and two women died in hospital. Eight patients (1 man, 7 women) have been resettled for a second time. The commonest reasons for readmission included increasing physical dependency, mental deterioration and dementia.

The experience in Leeds shows that in the reprovided services for a large number of mentally handicapped people discharged from long-stay hospital care it can be expected that a proportion ( $10 \%$ in this survey) will need readmission. Beds will be required for their assessment and treatment. For each 100 people discharged and longterm beds closed, 10 have been readmitted. Therefore, a provision of 10 new beds per 100 people discharged could well be necessary in resource planning to support the community services.

DOUglas A. SPEnCER, Consultant Psychiatrist, Leeds Community \& Mental Health Services, Leeds LS5 3EJ

\section{Patient or polyp?}

Sir: There has been much debate in recent years about the correct terminology for those individuals who receive services from the National Health Service and who were previously known as patients. Confusion appears to have increased about these people, an example of which is in a recent article in the Psychiatric Bulletin (Thomas et al, 1996, 20, 455-458) when, in the summary of the article, the authors use both client and patient to describe those individuals receiving treatment. It seems to me that the correspondence column in the Bulletin would be an ideal vehicle for moving this debate forward.

It is clear that terms such as client, user and consumer have not met with uniform acceptance. There are many other terms one could consider. Partner is one such term and would be in keeping with the business speak so beloved by management. To remind doctors of their role, one could consider the term polyp, according to the Concise English Dictionary, an individual in a compound organism of various kinds. Chartist, derived from the English Democratic Party who had their own People's Charter 150 years before John Major, might be looked upon favourably by Government. PUS (a Person who Uses Services) is a new and neutral term.

Your correspondents undoubtedly could contribute many other possibilities to the debate. If no satisfactory alternative is found it might be best to return to the term patient which derives from the Latin word, patti (=to suffer), and which means one who suffers or a person under medical treatment.

O. DALY, Consultant Psychiatrist, Lagan Valley Hospital, Lisburn BT28 1JP 